
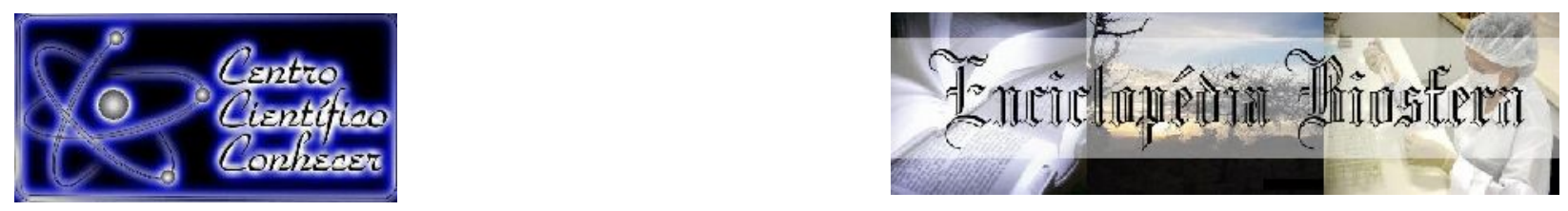

\title{
AVALIAÇÃO DA INFLUÊNCIA DA CULTURA ORGANIZACIONAL E DO PERFIL DOS COLABORADORES NO PROCESSO DE ATUALIZAÇÃO DA ISO 9001:2015 EM MINERADORAS DO MESMO CONGLOMERADO
}

\author{
João Paulo Félix Pires' ${ }^{\text {, Márcio do Carmo Boareto², Geraldo Sadoyama Leal }}{ }^{3}$ \\ 1 Mestrando em Gestão Organizacional pela Universidade Federal de Goiás UFCAT, \\ Catalão-GO, Brasil (jpfelixpires@hotmail.com). \\ 2 Mestrando em Gestão Organizacional pela Universidade Federal de Goiás (UFCAT), \\ Catalão-GO, Brasil. \\ 3 Professor Doutor do Mestrado em Gestão Organizacional da Universidade Federal de \\ Goiás (UFCAT), Catalão-GO, Brasil. \\ Recebido em: 04/10/2019 - Aprovado em: 30/11/2019 - Publicado em: 15/12/2019 \\ DOI: 10.18677/EnciBio_2019B6
}

\begin{abstract}
RESUMO
A norma NBR ISO 9001 é mundialmente utilizada auxiliando a implantação e manutenção do Sistema de Gestão da Qualidade (SGQ), guiando as empresas a atenderem aos requisitos de qualidade. Desde a sua origem a norma NBR ISO 9001 passou por quatro revisões (1994, 2000, 2008 e 2015), na revisão mais recente as empresas certificadas tiveram três anos para se adequarem a nova versão, o prazo se expirou em outubro de 2018. Este trabalho objetiva investigar como a cultura organizacional e o perfil dos colaboradores influencia e contribui no processo de transição da ISO. Optou-se por aplicar um estudo de caso de corte transversal em duas mineradoras do mesmo conglomerados e certificadas na ISO 9001. Para tal investigação, o instrumento de coleta de dados utilizado foi um questionário autoaplicável (survey). Os resultados do questionário estão apresentados por meio de estatística descritiva, informando média, desvio padrão, significância estatística e frequência. Conclui-se que para alcançar o sucesso na transição da ISO 9001 é necessário que o perfil dos colaboradores/facilitadores não ofereça resistência para transição e apresentem algumas características como: nível superior de escolaridade e posição de liderança dos facilitadores na empresa. A cultura organizacional da empresa deve estar alinhada com a cultura da matriz, foi constatado que a criação de subculturas organizacionais pode prejudicar a transição.
\end{abstract}

PALAVRAS-CHAVE: Cultura organizacional, ISSO 9001:2015, Sistema de gestão da qualidade.

\section{EVALUATION OF THE INFLUENCE OF ORGANIZATIONAL CULTURE AND EMPLOYEE PROFILE ON THE ISO 9001: 2015 UPDATE PROCESS IN MINING COMPANY OF THE SAME CONGLOMERATED}

\begin{abstract}
The NBR ISO 9001 standard is used worldwide to assist the implementation and maintenance of Quality Management Systems (QMS), guiding as companies to meet quality requirements. Since its inception in the NBR ISO 9001 standard has undergone four revisions (1994, 2000, 2008 and 2015), the most recent revision as
\end{abstract}


certified companies had three years to adapt a new version, the a deadline has expired in October 2018. The objective this paper is investigate how organizational culture and employee profile influence and contribute to the ISO transition process. We opted to apply a cross-sectional case study to two mining companies in the same conglomerate and certified to ISO 9001. For such investigation, the data collection instrument used was a self-administered questionnaire (survey). The results of the questionnaire are presented by descriptive statistics, mean, standard deviation, statistical significance and frequency. It is concluded that to achieving or succeeding in the transition from ISO 9001 requires that the profile of employees / facilitators does not offer resistance to transition and presents some characteristics such as: higher education level and leadership position of facilitators in the company. An organizational culture of the company must be aligned with the culture of the matrix, it was found that the creation of organizational subcultures can hinder the transition.

KEYWORDS: Quality Management System; ISO 9001:2015; organizational culture.

\section{INTRODUÇÃO}

A demanda de criar uma norma internacional de padronização para um determinado serviço ou produto surgiu durante o período da segunda guerra mundial, com objetivo de desenvolver procedimentos de normalização na fabricação de munições, dando início a uma série de normas para uniformizar a produção bélica. Antes dessa iniciativa não existia nenhuma norma internacional de padronização, isso inviabilizou que os países aliados compartilhassem suas munições (TAJRA, 2008).

No período pós-guerra, grandes potências como o Japão e a Alemanha estavam devastadas pelos efeitos da guerra e perceberam a necessidade de partir para a industrialização como forma de evitar a extinção, importando matéria-prima insuficiente por lá e exportando produtos industrializados, desta forma, nunca antes na história o comércio entre países foi tão intenso. Para ter um comércio leal entre os países, foi necessário criar um modelo mínimo de padrão (TAJRA, 2008).

Sendo assim, durante o período pós-guerra foi realizada uma reunião em Londres, capital da Inglaterra, com executivos e diretores de 25 países, incluindo o Brasil. A pauta da reunião foi a criação de uma organização internacional não governamental com o foco em unificar as normas industriais, criando um padrão internacional de qualidade (FERNÁNDEZ; MATEO, 2016).

Após dois anos discutindo o assunto, 157 países se reuniram e criaram a ISO (International Organization for Standardization em português Organização Internacional para Padronização), com sede em Genebra, capital da Suíça. Teve o início oficial em 23 de fevereiro de 1947 e tinha a finalidade de criar padrões e elementos regulatórios para o comércio mundial (FERNÁNDEZ; MATEO, 2016).

Em 1987 ocorreu o início de um novo caminho para a qualidade, foi realizado - lançamento da primeira versão da ISO $9001^{1}$ publicada pela Organização Internacional para Padronização (CHAVES; CAMPELLO, 2016). A norma ISO 9001 tornou-se uma poderosa ferramenta, sendo utilizada para o gerenciamento da qualidade em todos os tipos de organizações - mineração, automobilística,

\footnotetext{
1 A sigla "ISO" foi originada da palavra isonomia, sinônimo de igualdade, cujo objetivo é a padronização do gerenciamento do sistema da qualidade. "9000" é o código dado a todas as normas criada pelo comitê técnico TC-176. "9001" significa que a norma é certificável pois termina com final "01".
} 
alimentação, farmacêutica entre outras - não somente empresas com manufatura de produtos, mas também organizações que prestam serviços (FONSECA, 2015).

Atualmente, mais de um milhão de empresas (em 191 países) são certificadas na ISO 9001. Somente na América do Sul são 44 mil empresas, sendo o Brasil o país com maior número de certificações (ISO, 2017). Devido ao reconhecimento internacional do selo, as empresas que o possui, abrem as suas portas para o mercado externo, podendo negociar tanto dentro quanto fora do país.

A mais recente versão da ISO 9001 teve seu lançamento em setembro de 2015. Antes dessa, foram publicadas as versões 1987, 1994, 2000 e 2008. Em todas sempre buscou-se o aprimoramento e a melhoria continua para refletir os avanços na tecnologia e aplicação da gestão da qualidade. As mudanças realizadas na versão 2015 foram necessárias para que a ISO 9001 se adaptasse as alterações que ocorreram nas organizações, que encontram-se inseridas em um mercado altamente competitivo e dinâmico, onde a manutenção de clientes se tornou uma tarefa muito complexa, não deixando margem para burocracias ou morosidades (CHAVES; CAMPELLO, 2016).

Neste documento será estudada a transição da norma ISO 9001, pois, a mesma é recente e há escassez de pesquisas que investiguem o processo de transição. O problema de pesquisa abordado refere-se à necessidade de avaliar qual a influência da cultura organizacional e do perfil de colaboradores no processo de atualização da ISO em mineradoras do mesmo conglomerados. Para responder a esta questão será analisado com detalhe e profundidade a percepção dos participantes da pesquisa que trabalham em duas mineradoras certificadas na ISO 9001:2015, para isso será utilizado como instrumento de coleta de dados um questionário autoaplicável com 31 questões.

Desta forma o objetivo deste estudo foi desenvolver, analisar e compreender a influência do perfil dos colaboradores e da cultura organizacional no processo de atualização da ISO em empresas multinacionais do mesmo conglomerado.

\section{MATERIAL E MÉTODOS}

Optou-se por aplicar um estudo de caso de corte transversal, ou seja, a coleta foi realizada em um dado ponto no tempo em duas mineradoras do mesmo conglomerado e certificadas na ISO 9001:2015. Segundo Andrade (2017) o estudo de caso é o método mais indicado, quando a investigação deseja examinar e descrever os acontecimentos. Esse tipo de delineamento é caracterizado com um tipo de investigação que se propõe explanar de forma sistematizada os fatos que aconteceram em um determinado contexto.

Para realizar a coleta de dados do estudo de caso, foi utilizado um questionário do tipo survey, enviado eletronicamente por meio de e-mail para os participantes da pesquisa que trabalha nas duas mineradoras certificadas na ISO 9001:2015. Segundo Babbie (1999), a investigação com questionários também conhecida como survey, termo em inglês, deverá ser utilizada em pesquisas de abordagem quantitativa, que tem como objetivo representar as opiniões e características dos entrevistados.

O questionário utilizado no estudo de caso está disponível no quadro 1. Ele foi estruturado com duas seções, as questões da seção 01 foram utilizadas com objetivo de identificar e caracterizar o perfil dos participantes respondentes e a sua respectiva área. Sendo que a primeira seção contém questões abertas e fechadas, nas questões abertas o entrevistado responde com suas palavras, esse tipo de 
questão pode dificultar a codificação, tabulação e interpretação, desta maneira, serão utilizadas em apenas três ocasiões. Já as questões fechadas foram 3 do tipo múltipla escolha, e 5 do tipo dicotômica, contendo escalas nominais e escalas ordinais.

Já a segunda seção possui apenas questões fechadas contendo escala Likert. Essa seção tem o objetivo de identificar os itens que representam as principais dificuldades que o sistema de gestão da qualidade enfrentou durante a transição de versão, além de apontar os principais desafios enfrentados mesmo após obtenção da certificação, sendo subdividida em 5 partes. A primeira parte abordará questões voltadas a cláusula sobre o planejamento de mudanças; a segunda abordará sobre a documentação da empresa; a terceira abordará a cláusula sobre liderança; já a quarta conterá questões mediante a gestão de risco; e por fim a quinta irá tratar de generalidades, ou seja, as outras cláusulas que receberam alterações na mudança de versão.

QUADRO 1 - Questionário autoaplicável direcionado aos participantes da pesquisa

\begin{tabular}{|c|c|}
\hline 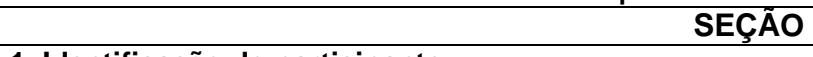 & \\
\hline 1. Identificação do participante & \\
\hline 2. Cargo & \\
\hline 3. Departamento & \\
\hline 4. Sexo & ( ) Feminino ( ) Masculino ( )Não declarar \\
\hline 5. Idade: & 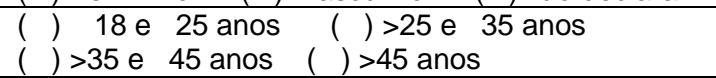 \\
\hline $\begin{array}{l}\text { 6. Tempo de empresa como facilitador do Sistema de } \\
\text { gestão da qualidade (SGQ): }\end{array}$ & 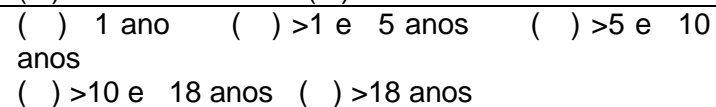 \\
\hline 7. Escolaridade: & $\begin{array}{l}\text { ( ) Médio ( ) Superior ( ) Pós-graduação } \\
\text { () Mestrado ( ) Doutorado ( ) Pós-Doutorado }\end{array}$ \\
\hline 8. Acompanhou a transição da norma ISO 9001:2015? & ( ) Sim ( ) Não \\
\hline As questões 9 e 10 somente devem ser respondida & em caso de resposta positiva na questão 8: \\
\hline $\begin{array}{l}\text { 9. Recebeu treinamento na interpretação da ISO } \\
\text { 9001:2015? }\end{array}$ & ( ) $\operatorname{Sim}$ ( ) Não \\
\hline $\begin{array}{lcccc}10 . & \text { Em algum } & \text { momento } & \text { você } & \text { recebeu } \\
\text { orientação/treinamento da equipe } & \text { que } & \text { prestou } \\
\text { consultoria durante a transição da ISO? } & & \\
\end{array}$ & ( ) Sim ( ) Não \\
\hline $\begin{array}{l}\text { 11. Em caso de responder 'Sim' para a questão anterior: } \\
\text { você concorda que a consultoria facilitou para a } \\
\text { transição da ISO dentro da organização? }\end{array}$ & ( ) Sim ( ) Não ( ) Indiferente \\
\hline $\begin{array}{ll} & \text { SEÇÃO }\end{array}$ & \\
\hline Parte 1. Planejamento de Mudança (gestão de mudanç & \\
\hline $\begin{array}{l}\text { 1.1. Os colaboradores do processo onde você atua não tivera } \\
\text { (gestão de mudança) em sua rotina? }\end{array}$ & m resistência em aplicar o planejamento de mudanças \\
\hline $\begin{array}{l}\text { 1.2. O planejamento das mudanças facilita a evolução da em } \\
\text { do dia-a-dia? }\end{array}$ & oresa e a sua realização não burocratiza as atividades \\
\hline $\begin{array}{l}\text { 1.3. Os colaboradores concordam que nenhuma mudança } \\
\text { planejamento de mudança, mesmo quando existe uma neces }\end{array}$ & $\begin{array}{l}\text { na área deve ocorrer sem a realização previa do } \\
\text { sidade de rápida entrega? }\end{array}$ \\
\hline $\begin{array}{l}\text { 1.4. Os colaboradores do processo onde você atua enxergam } \\
\text { evitar imprevistos? }\end{array}$ & que o planejamento de mudanças ajuda a empresa a \\
\hline Parte 2. Informação documentada: & \\
\hline $\begin{array}{l}\text { 2.1. Você fez poucas adequações na documentação } \\
\text { responsabilidade, durante o processo de transição da ISO } 90\end{array}$ & $\begin{array}{l}\text { orocedimentos e instruções de trabalho) sob sua } \\
1: 2015 \text { ? }\end{array}$ \\
\hline 2.2. A ausência de obrigatoriedade de alguns documentos na & ISO 9001:2015 tornou a transição mais fácil? \\
\hline Parte 3. Liderança & \\
\hline $\begin{array}{l}\text { 3.1. A alta liderança da área onde você atua não demonstr } \\
\text { sistema de gestão? }\end{array}$ & ou resistência em aumentar seu envolvimento com o \\
\hline $\begin{array}{l}\text { 3.2. Os gestores (alta liderança) da sua área entendem } \\
\text { fundamental para atingir bons resultados durante auditoria e }\end{array}$ & $\begin{array}{l}\text { que o seu envolvido com o sistema de gestão é } \\
\text { nanter a conformidade dos seus produtos/serviços? }\end{array}$ \\
\hline $\begin{array}{l}\text { 3.3. Quando comparada com a versão anterior, a ISO } 900 \\
\text { SGQ? }\end{array}$ & 1:2015 facilita o envolvimento da alta direção com o \\
\hline Parte 4. Gestão de risco & \\
\hline 4.1. Durante o período de transição o processo onde & \\
\hline
\end{tabular}


4.2. Os colaboradores da sua área tiveram facilidade em compreender os riscos operacionais estabelecidos?

4.3. Os colaboradores da sua área tiveram facilidade em compreender os riscos estratégicos estabelecidos?

4.4. Sempre que ocorre mudanças nos processos/atividades, os responsáveis pela gestão de risco atuam a fim de mapear os riscos referente a nova atividade?

Parte 5. Generalidades

5.1. Quando comparada com a versão anterior, a ISO 9001:2015 está mais clara, facilitando sua implementação?

5.2. O processo/departamento tiveram mais facilidade para se preparar para auditoria da ISO $9001: 2015$ do que na versão anterior?

5.3. Quando comparada com a versão anterior, a ISO 9001:2015 reduziu a burocracia no processo onde você atua?

5.4. Todos os funcionários do seu departamento têm facilidade em entender quem são seus clientes interno e externos?

5.5. A ISO 9001:2015 facilitou na definição dos indicadores de desempenho de qualidade do processo onde você atua?

5.6. Quando comparada com a versão anterior, a ISO 9001:2015 estimula com mais intensidade a aplicação da melhoria contínua no processo onde você atua?

5.7. A organização teve dificuldade em definir o contexto organizacional e repassar para o processo onde você atua?

Fonte: Autoria própria

Com base na escala Likert o respondente teve cinco opções de respostas fechadas. Foi utilizada a escala de valores de 1 a 5 também conhecido como escala Likert de cinco pontos. Esse método de escala permite medir as opiniões e conhecer o grau de conformidade do respondente com qualquer pergunta apresentada. De acordo com Likert (1932) é recomendado ancorar a escala com palavras nas extremidades, desenvolvendo uma escala simétrica que contenha ponto neutro. $\mathrm{A}$ FIGURA representa uma escala do tipo Likert com o respectivo significado dos cinco pontos (Discordo totalmente, discordo, indiferente, concordo e concordo totalmente).

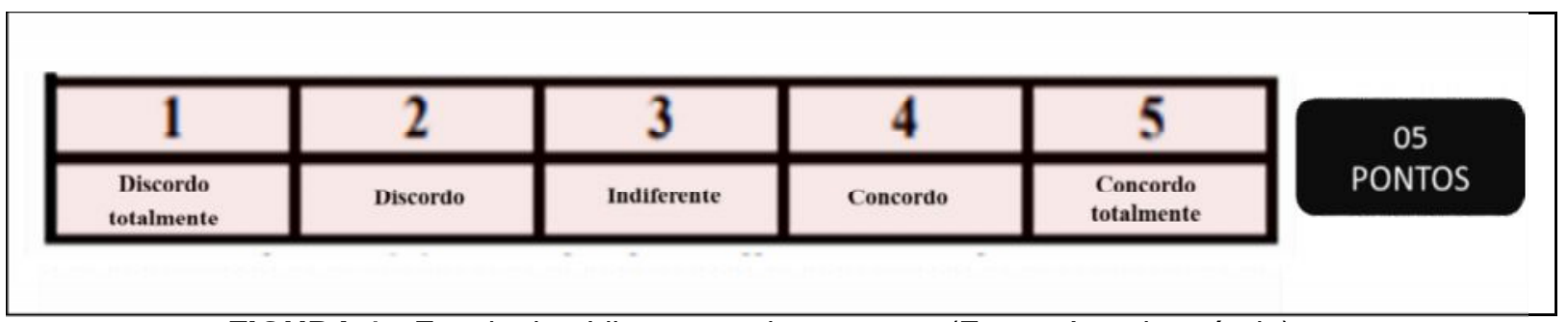

FIGURA 1 - Escala tipo Likert com cinco pontos (Fonte: Autoria própria).

Ao todo o questionário tem 31 questões (11 na seção 01 e 20 na seção 02). Um teste piloto foi realizado, com intuito de verificar o funcionamento adequado, eliminando possíveis inconsistências, ambiguidades ou complexidades do questionário.

O teste piloto foi direcionado aos participantes responsáveis do departamento de sistema de gestão da qualidade em cada uma das empresas. Os participantes gastaram em média oito minutos, a partir do teste piloto surgiram alguns pontos de melhoria: redação, estrutura e aparência do questionário.

\section{Local de estudo}

A pesquisa foi realizada em duas mineradoras (filiais) do sudeste goiano, as duas empresas são partes do mesmo conglomerado (matriz). No ano de 2017 ambas foram certificadas na ISO 9001:2015, sendo que anteriormente eram certificadas na versão 2008. A empresa 1 tem um pouco mais de 43 anos de história já a empresa 2 um pouco mais de 35 anos, ambas são referências de inovação e qualidade de produtos, sendo certificadas na ISO 9001 desde a década de 90. As 
empresas são de grande porte e possuem aproximadamente 2300 e 2000 colaboradores respectivamente.

\section{Desenho do estudo}

Foram realizadas duas reuniões, uma em cada mineradora, todos os facilitadores foram convidados para participarem, os mesmos puderam compreender o funcionamento do survey eletrônico e tiraram todas as dúvidas relacionadas as perguntas questionadas, os que não puderem participar da reunião foram contatados via telefone.

Feito o contato com os participantes da pesquisa nas duas empresas, o envio do questionário foi realizado de imediato, ao receber o questionário o próprio entrevistado realizou o preenchimento com base nas respostas que lhe foram colocadas. Os participantes da pesquisa que não responderam o questionário receberam o link novamente, com o intervalo de uma semana e esse processo se repetiu por mais duas vezes. A coleta de dados foi realizada no mês de julho de 2019.

\section{População, amostra e tamanho da amostra}

A população são os facilitadores ${ }^{2}$ do $S G Q$ das duas mineradoras multinacionais (Empresa 1 e Empresa 2). Ao todo são 55 facilitadores, sendo 35 na empresa 1 e 20 na empresa 2. A escolha dessa população foi estratégica, pois, apesar da gestão da qualidade ser praticada por todos dentro da organização, estes são pontos focais da qualidade nas suas respectivas áreas, sendo assim, eles terão maior capacidade de responder ao questionário por possuirem melhor treinamento e conhecimento da ISO 9001:2015 do que os demais colaboradores. Além disso, os mesmos estão presentes em todas as áreas da empresa, desde o chão de fábrica até as áreas administrativas, com diversificadas formações: engenheiros, técnicos, administradores, químicos entre outros. Deste modo, eles conseguiram representar a empresa como um todo, não se restringindo apenas à uma área.

As amostras são os colaboradores da empresa com função de facilitadores do SGQ que participaram do preenchimento do questionário, sendo 23 facilitadores da empresa 1 e 13 facilitadores na empresa 2.

Para realizar o cálculo de confiança do tamanho da amostra, foi utilizada a plataforma virtual OpenEpi, Versão 3 no site: https://www.openepi.com/Menu/OE_Menu.htm. A equação 1 representa a formula utilizada para realizar o cálculo de confiança.

Onde:

$$
n=\left[\operatorname{EDFF}^{*} N p(1-p)\right] /\left[\left(d 2 / Z 21-\alpha / 2^{*}(N-1)+p^{*}(1-p)\right]\right.
$$

Tamanho da amostra (fator de correção da amostra finita ou fcp) $=\mathrm{N}=5$

Frequência \% hipotética do fator do resultado na população $=p=50 \%+/-10$

Limites de confiança como \% de 100(absoluto $+/-\%$ ) $=\mathrm{d}=10 \%$

Efeito de desenho $=$ EDFF $=1$

Tamanho da amostra $=\mathrm{n}=$ ?

\footnotetext{
${ }^{2}$ Os facilitadores são colaboradores dos mais variados cargos (auxiliares, engenheiros, especialistas, operadores, químicos, técnicos entre outros) responsáveis por gerenciar a qualidade em suas respectivas áreas. Por meio das diretrizes fornecidas pelos colaboradores do departamento de sistema de gestão da qualidade.
} 
O valor de $n$ encontrado ao aplicar a formula é 36 , isso significa que o intervalo de confiança do tamanho da amostra é de 95\%, conforme retirado da tabela disponibilizada no OpenEpi.

\section{Perfil dos Entrevistados}

\section{RESULTADOS E DISCUSSÃO}

De um total de 55 profissionais permanentes do quadro de facilitadores do sistema de gestão das duas unidades, 53 estavam ativos em suas funções no intervalo relativo à coleta. Dos 53 ativos, 40 participaram da pesquisa, uma taxa de devolução de $75,4 \%$, essa excelente taxa de devolução é justificada devido ao método de convite utilizado, entrar em contato com os entrevistados antes de enviar a pesquisa aumentou a taxa de resposta. Todos os 40 participantes preencheram o questionário por completo, resultando em uma taxa de validação do preenchimento de $100 \%$, isso se dá pois o survey foi parametrizado para enviar a resposta somente quando todas as perguntas obrigatórias fossem devidamente preenchidas.

Esta pesquisa contou com a participação de coordenadores, analistas, engenheiros, operadores, supervisores, técnicos, enfermeiros e assistentes conforme pode ser observado na Tabela 1. De acordo com a distribuição na escala daquele período, os profissionais analistas tiveram, proporcionalmente, menor participação do preenchimento, apenas 55\%. As demais funções todas com uma aderência superior a $70 \%$.

Para cargos de liderança (coordenadores e supervisores) a participação foi de $18 \%$, cargos de mão de obra especializada (Engenheiros e analistas) $23 \%$, funções de campo (Técnicos e Operadores) 36\%, cargos administrativos (Assistentes) $20 \%$ e funções da área de saúde (Enfermeiros) $5 \%$.

Facilitadores com cargo de liderança ou engenheiro representa $24 \%$ na empresa 1 e $29 \%$ na empresa 2 . Ter facilitadores com posição de chefia na empresa facilita a transição pois esses cargos possuem mais autonomia de trabalho além de influenciar outros colaboradores do seu departamento que são seus subordinados. A aderência de todos da organização é fundamental para transição eficaz da ISO 9001:2015. Segundo Roa et al., (2018) níveis de liderança tendem a colaborar com mudanças pois percebem positivamente suas habilidades e competências individuais para contribuir para a mudança, gerando nos outros colaboradores o sentimento e desejo de participarem no processo de mudança organizacional.

TABELA 1 - Número e porcentagem de questionários válidos distribuídos de acordo com os cargos e o número de funcionários

\begin{tabular}{|c|c|c|c|c|c|c|c|c|c|c|c|c|}
\hline \multirow{3}{*}{ CARGOS } & \multicolumn{4}{|c|}{ EMPRESA 01} & \multicolumn{4}{|c|}{ EMPRESA 02} & \multicolumn{4}{|c|}{ TOTAL } \\
\hline & \multirow{2}{*}{$\begin{array}{c}\text { Total } \\
(\mathrm{N})\end{array}$} & \multicolumn{2}{|c|}{$\begin{array}{l}\text { Question. } \\
\text { Validos }\end{array}$} & \multirow{2}{*}{$\begin{array}{c}\text { Frequenc. } \\
\text { por cargo } \\
(\%)\end{array}$} & \multirow{2}{*}{$\begin{array}{l}\text { Total } \\
(\mathrm{N}) \\
\end{array}$} & \multicolumn{2}{|c|}{$\begin{array}{l}\text { Question. } \\
\text { Validos }\end{array}$} & \multirow{2}{*}{$\begin{array}{c}\text { Frequenc. } \\
\text { por cargo } \\
(\%)\end{array}$} & \multirow{2}{*}{$\begin{array}{l}\text { Total } \\
\text { (N) }\end{array}$} & \multirow{2}{*}{\multicolumn{2}{|c|}{$\begin{array}{l}\text { Question. } \\
\text { Validos } \\
\text { (N) (\%) }\end{array}$}} & \multirow{2}{*}{$\begin{array}{c}\text { Frequenc. } \\
\text { por cargo } \\
(\%)\end{array}$} \\
\hline & & (N) & (\%) & & & $(\mathrm{N})$ & $(\%)$ & & & & & \\
\hline Analista & 7 & 3 & $43 \%$ & $12 \%$ & 4 & 3 & $75 \%$ & $21 \%$ & 11 & 6 & $55 \%$ & $15 \%$ \\
\hline Assistente & 6 & 6 & $100 \%$ & $23 \%$ & 4 & 2 & $50 \%$ & $14 \%$ & 10 & 8 & $80 \%$ & $20 \%$ \\
\hline Coordenador & 2 & 2 & $100 \%$ & $8 \%$ & - & - & - & - & 2 & 2 & $100 \%$ & $5 \%$ \\
\hline Enfermeiro & 1 & 1 & $100 \%$ & $4 \%$ & 1 & 1 & $100 \%$ & $7 \%$ & 2 & 2 & $100 \%$ & $5 \%$ \\
\hline Engenheiro & 4 & 3 & $75 \%$ & $12 \%$ & - & - & - & - & 4 & 3 & $75 \%$ & $8 \%$ \\
\hline Operador & 2 & 1 & $50 \%$ & $4 \%$ & 2 & 2 & $100 \%$ & $14 \%$ & 4 & 3 & $75 \%$ & $8 \%$ \\
\hline Supervisor & 3 & 1 & $33 \%$ & $4 \%$ & 4 & 4 & $100 \%$ & $29 \%$ & 7 & 5 & $71 \%$ & $13 \%$ \\
\hline Técnico & 10 & 9 & $90 \%$ & $35 \%$ & 5 & 2 & $40 \%$ & $14 \%$ & 15 & 11 & $73 \%$ & $28 \%$ \\
\hline Total Geral & 35 & 26 & $74 \%$ & $100 \%$ & 20 & 14 & $70 \%$ & $100 \%$ & 55 & 40 & $73 \%$ & $100 \%$ \\
\hline
\end{tabular}

Fonte: Autoria Própria 
Com relação ao gênero dos participantes a maioria foi constituída pelo sexo feminino (58,5\%), com a seguinte distribuição: 24 femininos e 17 masculinos, sem diferença estatisticamente significante entre as duas empresas $(p>0,05)$. Verificouse predomínio de mulheres na maioria das funções com exceção ao cargo de operador, essas informações podem ser visualizas na tabela abaixo.

TABELA 2 - Distribuição da categoria profissional de acordo com o gênero

\begin{tabular}{|c|c|c|c|c|c|c|c|}
\hline \multirow{3}{*}{ CARGOS } & \multicolumn{2}{|c|}{ EMPRESA 01} & \multicolumn{3}{|c|}{ EMPRESA 02} & \multicolumn{2}{|c|}{ TOTAL } \\
\hline & \multirow{2}{*}{\begin{tabular}{|c|c|}
\multicolumn{2}{|c}{ Masculino } \\
(N) $(\%)$
\end{tabular}} & Feminino & Masculino & \multicolumn{2}{|c|}{ Feminino } & Masculino & Feminino \\
\hline & & $\begin{array}{ll}(\mathrm{N}) & (\%)\end{array}$ & \begin{tabular}{l|l} 
(N) & (\%)
\end{tabular} & (N) & \begin{tabular}{|l|}
$(\%)$ \\
\end{tabular} & \begin{tabular}{l|l} 
(N) & (\%)
\end{tabular} & \begin{tabular}{l|l}
$(\mathrm{N})$ & $(\%)$ \\
\end{tabular} \\
\hline Analista & $28 \%$ & $14 \%$ & $17 \%$ & 2 & $13 \%$ & $37 \%$ & $37 \%$ \\
\hline Assistente & $14 \%$ & $5 \quad 19 \%$ & $17 \%$ & 2 & $13 \%$ & $25 \%$ & $7 \quad 17 \%$ \\
\hline Coordenador & $14 \%$ & $14 \%$ & -- & - & - & $12 \%$ & $12 \%$ \\
\hline Enfermeiro & -- & $14 \%$ & $17 \%$ & - & - & $12 \%$ & $12 \%$ \\
\hline Engenheiro & $14 \%$ & $28 \%$ & -- & - & - & $12 \%$ & $25 \%$ \\
\hline Operador & $14 \%$ & -- & $213 \%$ & - & - & $37 \%$ & $0-$ \\
\hline Supervisor & $0 \%$ & $14 \%$ & $17 \%$ & 3 & $20 \%$ & $12 \%$ & $4 \quad 10 \%$ \\
\hline Técnico & $\begin{array}{ll}312 \% \\
\end{array}$ & $623 \%$ & $213 \%$ & - & - & $512 \%$ & $615 \%$ \\
\hline Total Geral & $935 \%$ & $1765 \%$ & $\begin{array}{ll}8 & 53 \%\end{array}$ & 7 & $47 \%$ & $1741,5 \%$ & $2458,5 \%$ \\
\hline
\end{tabular}

Fonte: Autoria Própria

A distribuição por departamento foi agrupado em 9 gerencias: administração (8 facilitadores), mina (7 facilitadores), Segurança e Meio Ambiente (SSD) (6 facilitadores), operação/beneficiamento (5 facilitadores), manutenção (3 facilitadores), projetos/engenharia (3 facilitadores), laboratório (3 facilitadores), SGI (3 facilitadores) e logística (2 facilitadores), a distribuição está representado na figura 2. Observa-se a heterogeneidade da amostra, que é composta por facilitadores de todas as áreas da organização.

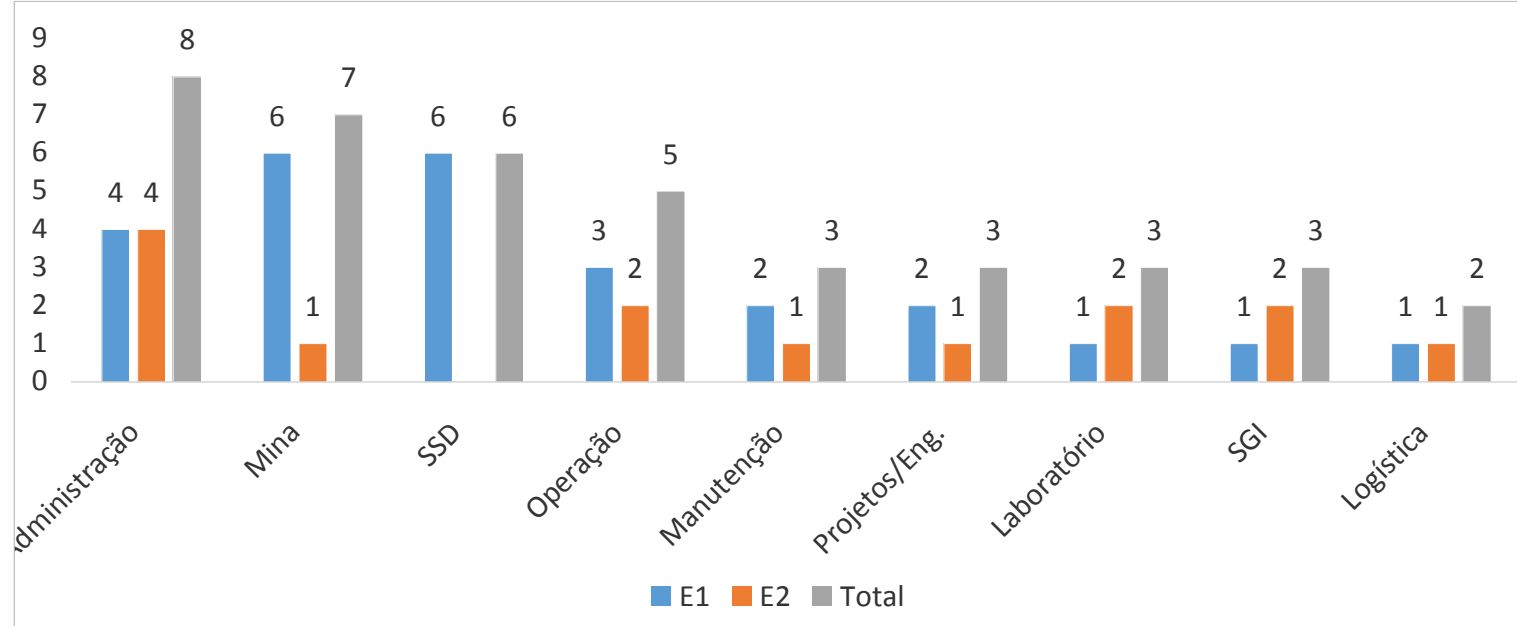

FIGURA 2 - Distribuição dos facilitadores de acordo com a gerencia (Fonte: Autoria Própria).

A distribuição dos facilitadores por idade está representada na figura 3 podese observar que a maioria dos profissionais que trabalham com sistema de gestão da qualidade tem entre 26 a 35 anos (22 facilitadores) seguido por profissionais entre 36 a 45 anos ( 11 facilitadores), sendo poucos profissionais com mais de 45 anos (2 facilitadores). A distribuição de idade dos facilitadores está sem diferença 
estatisticamente significante entre as duas empresas $(p>0,05)$, por meio do teste qui-quadrado obteve-se $\mathrm{p}=0,184$.

Analisando a questão da idade por empresa, observa-se que na empresa 2 existe o predomínio de facilitadores mais velhos, sendo que $50 \%$ dos facilitadores possuem mais de 35 anos. Já a empresa 01 possui apenas $23 \%$ dos facilitadores com idade superior a 35 anos.

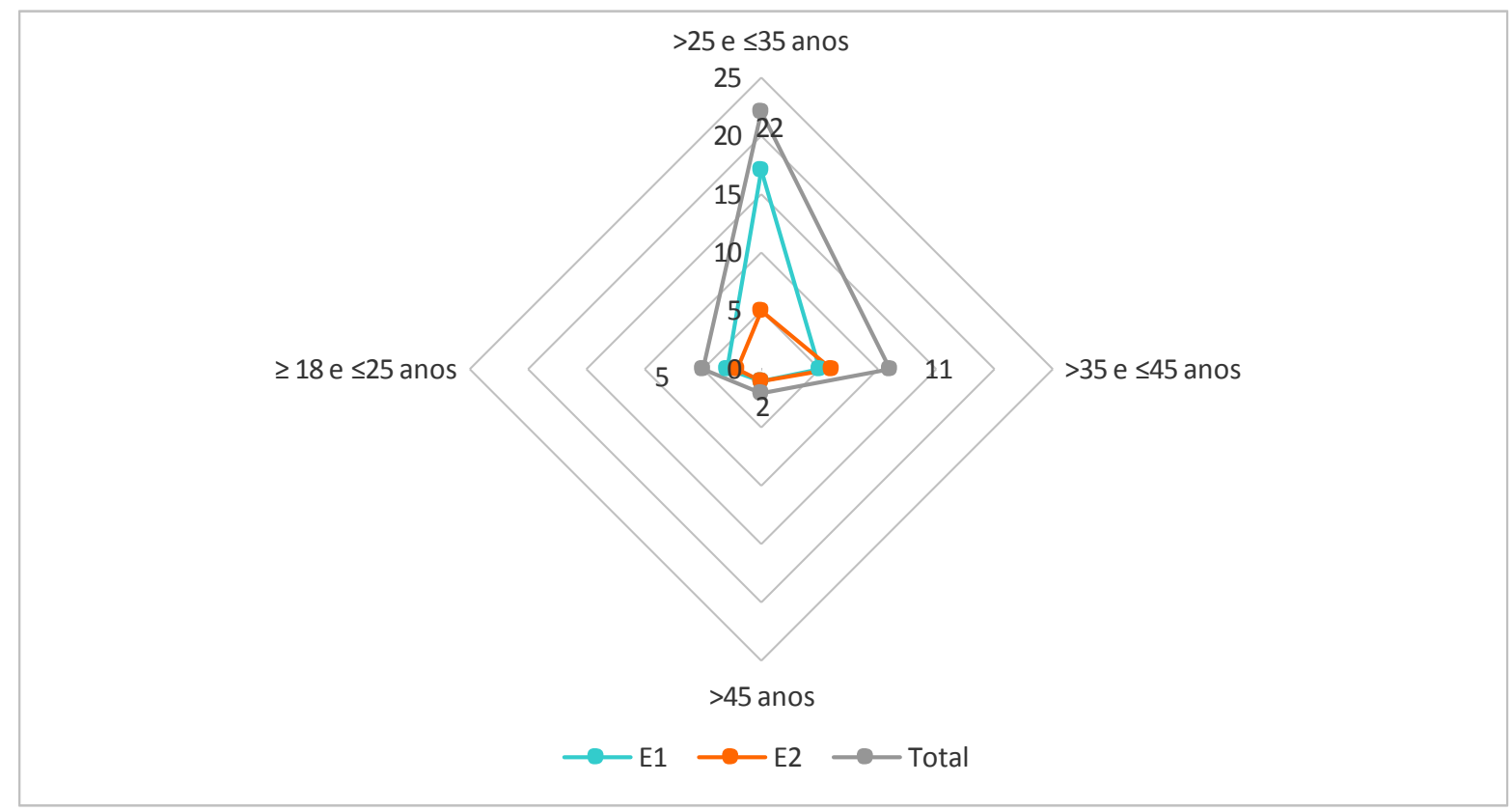

FIGURA 3 - Distribuição dos facilitadores por idade (Fonte: Autoria Própria)

A distribuição dos profissionais do sistema de gestão quanto ao tempo de experiência, independente da classe profissional, foi feita de acordo com o instrumento original, sendo realizado a dicotomização da variável tempo de experiência após o agrupamento da faixa de tempo, como pode ser observado na figura 4, 10 dos colaboradores (25\%) exercem a função de facilitador do sistema de gestão da qualidade a menos de 1 ano, 19 colaboradores (48\%) já atuam como facilitador com experiência entre $>1$ e $\leq 5$ anos, 6 colaboradores (15\%) com experiência de facilitador $>5$ e $\leq 10$ anos, 4 colaboradores (10\%) com longo tempo de experiência (>10 e $\leq 18$ anos) e apenas 1 colaborador (3\%) com mais de 18 anos de experiência. Esse agrupamento irá ajudar analisar possíveis interferências quanto da experiência profissional nas atitudes de trabalho. A distribuição de tempo de função está sem diferença estatisticamente significante entre as duas empresas $(p>$ $0,05)$, por meio do teste qui-quadrado tem $p=0,632$. 


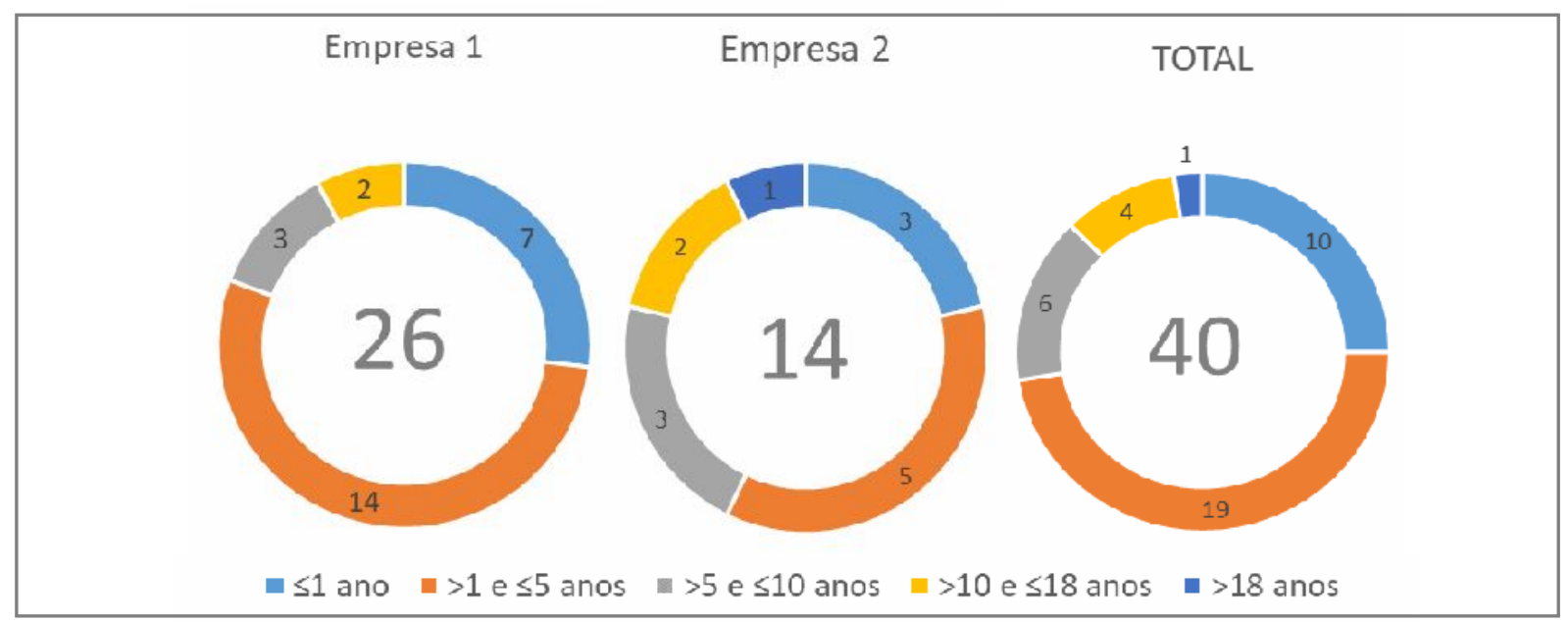

FIGURA 4 - Distribuição dos facilitadores por tempo de experiência com SGQ (Fonte: Autoria Própria)

Na empresa 1 apenas 19\% dos facilitadores possuem mais de cinco anos de experiência com SGQ, já na empresa 2 esse número é bem maior $43 \%$ dos facilitadores.

Por esta primeira constatação do perfil dos facilitadores, segundo a teoria sobre comportamento e, principalmente, segundo Silva e Cintra (2015), é de se esperar que os facilitadores da empresa 2 com estas características de idade avançada e maior tempo de empresa, fossem pouco flexíveis e avessos à implantação de uma nova metodologia de trabalho, consequentemente, resistentes às mudanças, pois se encontram numa situação próxima a aposentadoria e numa fase em que a estabilidade é muito importante e desejável. Corroborando com essa ideia temos Roa et al., (2018) em sua pesquisa realizada em uma mineradora na região do Atacama ele obteve que aqueles que estão na faixa de 31 a 40 anos têm uma atitude de medo pela mudança.

A escolaridade dos participantes da pesquisa pode ser analisada na tabela 3 , a maior parte dos participantes possuem ensino superior totalizando $40 \%$, logo em seguida $30 \%$ dos participantes possui pós-graduação, $25 \%$ possui pelo menos o ensino médio e apenas $5 \%$ possui mestrado. Todos os funcionários apresentam uma boa formação escolar, sendo que uma parcela significativa (75\%) possui curso superior. A empresa 1 possui uma parcela maior de facilitadores com curso superior (81\%) sendo que na empresa 2 esse número é de 64\%. A distribuição de escolaridade entre as duas empresas está sem diferença estatisticamente significante $(p>0,05)$, por meio do teste qui-quadrado chegou em $p=0,600$.

$O$ aspecto da escolaridade deve ser considerado e pode ter forte influência positiva no comportamento dos facilitadores. O bom nível de formação escolar facilita a compreensão dos usuários quanto à necessidade e importância de implantação de mudanças que venham melhorar o desempenho da empresa e, consequentemente, trazer benefícios para o próprio empregado e seu departamento, isso inclui as mudanças na ISO:9001 que busca sempre a melhoria continua dos processos (SILVA; CINTRA 2015). 
TABELA 3 - Nível de escolaridade dos participantes da pesquisa

\begin{tabular}{l|c|c|c|c|c|c}
\hline \multirow{2}{*}{ Escolaridade } & \multicolumn{2}{|c|}{ EMPRESA 01 } & \multicolumn{2}{c|}{ EMPRESA 02 } & \multicolumn{2}{c}{ TOTAL } \\
\cline { 2 - 8 } & Freq. (N) & Percent. (\%) & Freq. (N) & Percent. (\%) & Freq. (N) & Percent. (\%) \\
\hline Médio & 5 & $19 \%$ & 5 & $36 \%$ & 10 & $25 \%$ \\
\hline Superior & 11 & $42 \%$ & 5 & $36 \%$ & 16 & $40 \%$ \\
\hline Pós-graduação & 8 & $31 \%$ & 4 & $29 \%$ & 12 & $30 \%$ \\
\hline Mestrado & 2 & $8 \%$ & - & - & 2 & $5 \%$ \\
\hline Total Geral & $\mathbf{2 6}$ & $\mathbf{1 0 0 \%}$ & $\mathbf{1 4}$ & $\mathbf{1 0 0 \%}$ & $\mathbf{4 0}$ & $\mathbf{1 0 0 \%}$ \\
\hline
\end{tabular}

Fonte: Autoria Própria

Na tabela 4 é possível analisar a quantidade de facilitadores que participaram da transição da ISO 9001:2015. Observa-se que na empresa 1 houve uma porcentagem maior de facilitadores que participaram da transição da ISO, 73\% dos facilitadores atuais, sendo que na empresa 2 somente $57 \%$ dos facilitadores participaram. A distribuição da participação entre as duas empresas está sem diferença estatisticamente significante $(p>0,05)$, por meio do teste qui-quadrado obteve-se $p=0,305$.

TABELA 4 - Análise do processo de transição da ISO 9001:2015

\begin{tabular}{|c|c|c|c|c|}
\hline \multirow{2}{*}{$\begin{array}{l}\text { Participou na } \\
\text { transição }\end{array}$} & Empresa 1 & Empresa 2 & \multicolumn{2}{|r|}{ Total } \\
\hline & N (\%) & N (\%) & & N (\%) \\
\hline Não & $(27 \%)$ & $(43 \%)$ & 13 & (33\%) \\
\hline Sim & $(73 \%)$ & (57\%) & 27 & $(68 \%)$ \\
\hline Total & $(100 \%)$ & $(100 \%)$ & 40 & $(100 \%)$ \\
\hline
\end{tabular}

Fonte: Autoria Própria

Dos 27 facilitadores que participaram da transição da ISO 9001:2015, foi avaliado o tipo de preparação a que eles foram submetidos, nesta etapa foi possível selecionar mais de uma opção de resposta, ou seja, é possível que a pessoa tenha recebido tanto apoio de consultoria quanto o treinamento de interpretação da ISO 9001:2015. Na tabela 5 observa-se alta aderência, 89\% de participação tanto nas iniciativas de treinamento quanto no apoio recebido da consultoria. Sendo que na empresa 1 a participação nos dois eventos foi ainda maior, sendo $90 \%$ de participação nos treinamentos e 95\% no apoio de consultoria. Na empresa 2 tiveram aderência de $87 \%$ nos treinamentos e $75 \%$ no suporte dado pela consultoria.

Com isso pode-se concluir que dentro do subgrupo dos facilitadores que participaram da transição, a empresa 1 continua se destacando positivamente em relação a empresa 2, isso porque fica claro que a aderência nas duas atividades simultaneamente foi relativamente maior que na empresa 2.

TABELA 5 - Caracterização do processo de transição da ISO 9001 pelos que acompanham a transição

\begin{tabular}{|c|c|c|c|c|c|c|c|c|c|c|c|c|}
\hline \multirow{2}{*}{ Preparação } & \multirow{2}{*}{\multicolumn{4}{|c|}{$\begin{array}{c}\text { Empresa } 1 \\
\mathrm{~N}(\%)\end{array}$}} & \multicolumn{4}{|c|}{$\begin{array}{c}\text { Empresa } 2 \\
\mathbf{N}(\%)\end{array}$} & \multicolumn{4}{|c|}{$\begin{array}{l}\text { Total } \\
\mathbf{N}(\%)\end{array}$} \\
\hline & & im & & Não & & Sim & & Não & & Sim & & Não \\
\hline $\begin{array}{l}\text { Treinamento e } \\
\text { interpretação }\end{array}$ & 17 & (90\%) & 2 & $(10 \%)$ & 7 & $(87 \%)$ & 1 & $(13 \%)$ & 24 & (89\%) & 3 & $(11 \%)$ \\
\hline $\begin{array}{c}\text { Apoio de } \\
\text { Consultoria }\end{array}$ & 18 & (95\%) & 1 & (5\%) & 6 & (75\%) & 2 & $(25 \%)$ & 24 & $(89 \%)$ & 3 & $(11 \%)$ \\
\hline
\end{tabular}

Fonte: Autoria Própria 
Na figura 5 observa-se a opinião dos facilitadores sobre a importância da consultoria durante o processo de transição, as respostas indicam que o apoio da consultoria facilitou e ajudou na preparação. Sendo que dos 24 colaboradores que receberam apoio da consultoria, 92\% concordam que o apoio da consultoria ajudou na transição e 8\% é indiferente quanto ao apoio da consultoria.

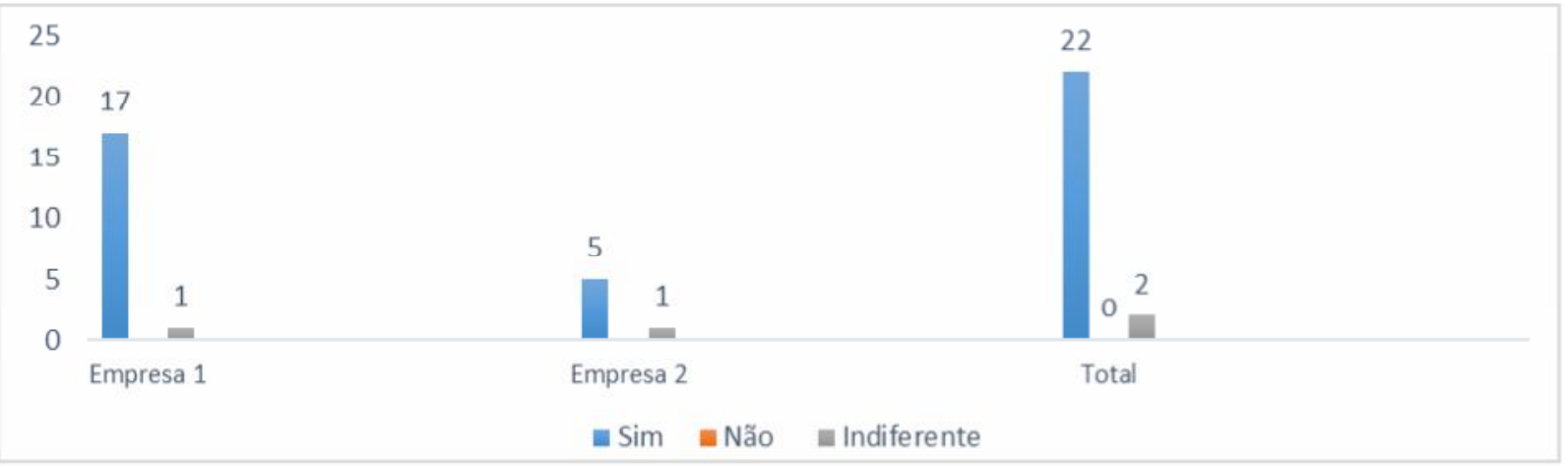

FIGURA 5 - Opinião sobre a importância da consultoria no processo de transição da ISO (Fonte: Autoria Própria)

$\mathrm{Na}$ análise das médias de respostas dos itens do questionário, não foram observadas diferenças estatisticamente significantes entre as duas empresas $(p>$ 0,05 ), isso pode ser visto na Tabela 6 , coluna 5 . O valor do $p$ value de cada item foi encontrado ao aplicar o teste T ou teste T de Student. Isso significa que aceitou-se a hipótese nula de nenhuma diferença estatística entre os grupos (Empresas).

Ainda na tabela 6 ao observar a última coluna, pode-se comparar a diferença da média de respostas entre empresa 1 e empresa 2. Observa-se que as notas da empresa 1 foi maior que da empresa 2 em 14 ocasiões, enquanto o inverso acontece apenas em 6 oportunidades.

TABELA 6 - Distribuição das médias e desvios padrões das empresas para cada item, levando em consideração o P-Value e a diferença das médias.

\begin{tabular}{|c|c|c|c|c|c|}
\hline \multirow{2}{*}{ Item } & EMPRESA 01 & EMPRESA 02 & TOTAL & \multirow{2}{*}{$P$ value } & \multirow{2}{*}{$\begin{array}{l}\text { Difer. } \\
\text { E1xE2 }\end{array}$} \\
\hline & $x \pm \sigma$ & $x \pm \sigma$ & $x \pm \sigma$ & & \\
\hline 1.1 & $60,58 \pm 27,54$ & $67,86 \pm 26,73$ & $63,13 \pm 27,14$ & 0,426 & $-7,28$ \\
\hline 1.2 & $71,15 \pm 23,12$ & $82,14 \pm 18,16$ & $75,00 \pm 21,93$ & 0,132 & $-10,99$ \\
\hline 1.3 & $65,38 \pm 26,53$ & $60,71 \pm 23,44$ & $63,75 \pm 25,29$ & 0,584 & 4,67 \\
\hline 1.4 & $81,73 \pm 16,67$ & $75,00 \pm 16,98$ & $79,38 \pm 16,88$ & 0,234 & 6,73 \\
\hline 2.1 & $54,81 \pm 25,51$ & $50,00 \pm 21,93$ & $53,13 \pm 24,14$ & 0,555 & 4,81 \\
\hline 2.2 & $63,46 \pm 22,62$ & $53,57 \pm 25,68$ & $60,00 \pm 23,89$ & 0,216 & 9,89 \\
\hline 3.1 & $68,27 \pm 24,04$ & $71,43 \pm 19,26$ & $69,38 \pm 22,28$ & 0,675 & $-3,16$ \\
\hline 3.2 & $75,00 \pm 25,50$ & $75,00 \pm 19,61$ & $75,00 \pm 23,34$ & 1,000 & 0,00 \\
\hline 3.3 & $73,08 \pm 23,37$ & $71,43 \pm 19,26$ & $72,50 \pm 21,78$ & 0,823 & 1,65 \\
\hline 4.1 & $65,38 \pm 24,57$ & $53,57 \pm 25,68$ & $61,25 \pm 25,29$ & 0,161 & 11,81 \\
\hline 4.2 & $72,12 \pm 24,83$ & $69,64 \pm 20,04$ & $71,25 \pm 23,03$ & 0,751 & 2,47 \\
\hline 4.3 & $66,95 \pm 23,39$ & $66,66 \pm 22,85$ & $66,88 \pm 22,92$ & 0,845 & 0,29 \\
\hline 4.4 & $66,35 \pm 25,44$ & $71,43 \pm 21,61$ & $68,13 \pm 24,01$ & 0,530 & $-5,08$ \\
\hline 5.1 & $72,12 \pm 17,79$ & $73,21 \pm 15,39$ & $72,50 \pm 16,79$ & 0,161 & $-1,10$ \\
\hline 5.2 & $67,31 \pm 18,40$ & $64,29 \pm 16,16$ & $66,25 \pm 17,50$ & 0,751 & 3,02 \\
\hline 5.3 & $62,50 \pm 19,04$ & $48,21 \pm 30,17$ & $57,50 \pm 24,15$ & 0,845 & 14,29 \\
\hline 5.4 & $73,08 \pm 21,12$ & $71,43 \pm 27,49$ & $72,50 \pm 23,20$ & 0,834 & 1,65 \\
\hline 5.5 & $74,04 \pm 18,00$ & $66,07 \pm 15,83$ & $71,25 \pm 17,50$ & 0,173 & 7,97 \\
\hline 5.6 & $75,00 \pm 15,81$ & $73,21 \pm$ & $74,38 \pm 16,49$ & 0,749 & 1,79 \\
\hline 5.7 & $50,96 \pm$ & $53,57 \pm$ & $\pm 22,21$ & 0,728 & $-2,61$ \\
\hline
\end{tabular}

Fonte: Autoria Própria 
No estudo do perfil do facilitador deve-se levar em consideração o maior número de informações possíveis. Uma análise superficial pode conduzir a um resultado tendencioso ou preconceituoso. Por exemplo, analisar somente a variável idade e a partir disso tirar conclusões. $O$ fato do indivíduo ser mais velho não significa, necessariamente, que ele tenha um perfil acomodado, ou que, não tenha ambição de se autodesenvolver e, portanto, que não tenha interesse em se submeter a uma nova metodologia de trabalho.

Segundo os autores Silva e Cintra (2015), se basear em um único traço para determinar, a personalidade ou as prováveis ações de um ser humano complexo é como pegar uma peça azul de um quebra cabeça e dizer se ela faz parte do céu, de uma piscina ou da parede de uma casa. Para traçar um perfil organizacional é necessário observar várias características e particularidades para forma um perfil dominante (RIBEIRO, 2016).

Neste estudo, pela finalidade, pelos resultados desejados e pela aplicabilidade pretendida, foram considerados e levantados, somente, informações facilmente observáveis: posição dos facilitadores na empresa, a idade, a formação, o tempo de serviço na empresa e as informações referentes à participação do facilitador durante a transição para nova metodologia. O resultado geral do perfil dos facilitadores nas duas empresas pode ser observado no quadro 2 .

Esses resultados revelam que a escolha dos facilitadores com posição de liderança nas duas empresas seguiu critérios semelhantes, pois a porcentagem é quase igual na empresa 1 e empresa 2, sendo $24 \%$ e $29 \%$ respectivamente. Quanto mais facilitadores a empresa tiver com perfil de liderança, melhor é, pois facilitadores com esta característica e posição formam um perfil francamente favorável a apoiar a transição, os lideres possuem muita mais autonomia para trabalhar e, portanto, podem gastar mais energia e tempo na transição da ISO, além de servir como inspiração para os funcionários da sua área e sob sua subordinação.

QUADRO 2 - Perfil dos facilitadores nas duas empresas

\begin{tabular}{|l|c|c|}
\hline \multicolumn{1}{|c|}{ Questão } & Empresa 1 & Empresa 2 \\
\hline Possuem cargo de liderança & $24 \%$ & $29 \%$ \\
\hline Possuem mais de 35 anos de idade & $23 \%$ & $50 \%$ \\
\hline Mais de 5 anos de experiência com SGQ & $19 \%$ & $43 \%$ \\
\hline Possui curso superior & $81 \%$ & $64 \%$ \\
\hline
\end{tabular}

Fonte: Autoria Própria.

Quanto ao fator idade e experiência com SGQ, observa-se que a empresa 2 possui um time de facilitadores com tendência de serem mais resistentes a mudança, pois $50 \%$ dos facilitadores possui mais de 35 anos e $43 \%$ com mais de cinco anos de experiência, ou seja, aproximadamente metade do time tem tendência a oferecer resistência em transições e mudanças, isso por que, a princípio têm receio de enfrentar uma nova metodologia, de perder poder ou prestígio em sua função, ter mudanças significativas nas tarefas e falta de perspectiva de melhora $\mathrm{com}$ as mudanças. A porcentagem de facilitadores com mais experiencia e idade é bem menor na empresa 1 , sendo $23 \%$ com mais de 35 anos e $19 \%$ com mais de cinco anos de experiência.

A respeito da influência do grau de formação dos facilitadores na aceitação da transição, por bibliografia sabe-se que colaboradores com curso superior são mais abertos a mudança, pois, estão dispostos a julgar as informações relativas a uma 
mudança antes de se posicionarem favoráveis ou contrários a mesma. Nesse sentido a empresa 1 tem um cenário melhor que a empresa 2, pois possui $81 \%$ de facilitadores com curso superior contra $64 \%$ da empresa 2.

Até agora foi analisado somente o perfil do usuário, no entanto, não depende somente do indivíduo, mas também, da situação e do ambiente em que ele se encontra. Segundo Silva e Cintra (2015), a cultura organizacional depende não só dos indivíduos, mais também do sistema de gestão, da estrutura organizacional, do relacionamento interpessoal, ou seja, o comportamento de uma mesma pessoa pode variar de acordo com o ambiente e/ou com a situação.

Segundo Chiavenato (2000), conforme citado por Ribeiro (2016) a cultura organizacional engloba aspectos formais, facilmente perceptíveis, relacionado a política, diretrizes, estrutura e procedimentos da empresa, além da percepção dos colaboradores que pode ser moldada por uma série de fatores.

Nesse sentido pode-se inferir que a participação dos facilitadores nos programas de preparação da transição está muito relacionada a subcultura organizacional em que a empresa está inserida.

No quadro 3, observa-se que a aderência dos facilitadores nos programas de transição da ISO foi bem melhor na empresa 1 do que na empresa 2. Isso é um indicativo que a empresa 2 possui uma subcultura diferente da cultura e expectativa da empresa matriz, outro indicativo é que por ter maior aderência ao processo de transição a empresa 1 chegou mais preparada no dia da auditoria, a comprovação disso é que nos 20 itens do questionário, em $70 \%$ destes a média da empresa 1 foi maior que da empresa 2. Lembrando que quanto maior a média do item, maior é a aderência da empresa naquele determinado item.

QUADRO 3 - Comparação da participação dos facilitadores nos programas de preparação da transição

\begin{tabular}{|l|c|c|}
\hline \multicolumn{1}{|c|}{ Questões } & Empresa 1 & Empresa 2 \\
\hline Participaram dos programas de transição da ISO & $73 \%$ & $57 \%$ \\
\hline Subgrupo que participou (Participação em treinamentos) & $90 \%$ & $87 \%$ \\
\hline $\begin{array}{l}\text { Subgrupo que participou (Participação nas atividades da } \\
\text { consultoria) }\end{array}$ & $95 \%$ & $75 \%$ \\
\hline $\begin{array}{l}\text { Quantidade de itens do check list com média maior durante o } \\
\text { comparativo }\end{array}$ & $70 \%$ & $30 \%$ \\
\hline
\end{tabular}

Fonte: Autoria Própria

\section{CONCLUSÃO}

O processo de transição foi eficaz nas duas empresas, pois no final da auditoria as duas organizações se certificaram na nova versão. O sucesso da transição pode se justificar pelo fato do time de facilitadores nas duas empresas ser constituído por profissionais com alto nível de instrução acadêmica, e uma parcela dos facilitadores (um pouco mais de $1 / 4$ do time) ser composta por cargos de liderança. A participação da liderança é fundamental na nova versão da ISO e também se mostrou um fator primordial durante a transição. Também é valido destacar a participação efetiva dos membros da organização em todos os níveis e áreas. Além disso, houve um bom planejamento e investimento da matriz em preparação, treinamento e consultoria.

Apesar das duas empresas conseguirem se certificar, a empresa 2 obteve mais desvios durante as auditorias do ano 2018 e 2019, recebendo não conformidades 3 vezes mais que a empresa 1. Algumas dessas não conformidades 
foram classificadas como maiores, colocando em xeque a re-certificação na nova versão da ISO. Essa performance inferior em relação a empresa irmã pode ser explicada por dois fatores: o perfil dos colaboradores/facilitadores e a cultura organizacional das duas organizações.

O resultado do perfil dos facilitadores da empresa 2 possui características e tendência de um grupo resistente a mudança, devido a fatores já discutidos. Em relação a cultura organizacional, apesar dos esforços da matriz em definir uma cultura de trabalho, ficou constatado a existência de subcultura dentro da empresa 2 influenciando apenas para participação parcial da transição. Essa subcultura organizacional exige atenção prioritária as atividades de rotina, fazendo com que atividades de aperfeiçoamento e desenvolvimento fiquem em segundo plano. Essas subculturas são coexistentes com a cultura maior que é disseminada pela matriz. Normalmente as subculturas coexistem dentro da organização, mesmo que hajam relações de conflito ou expectativas diferentes.

\section{REFERÊNCIAS}

ANDRADE, S. R.; BACKES, R. A.; PICCOLI, T.; SCHMITT, M. D.; FERREIRA, A; AMMON, X. A. C. O estudo de caso como método de pesquisa em enfermagem: uma revisão integrativa. Texto \& Contexto-Enfermagem, v. 26, n. 4, 2017. Disponivel em <http://www.scielo.br/pdf/tce/v26n4/0104-0707-tce-26-04e5360016.pdf>

BABBIE, E. Métodos de pesquisas de survey. Belo Horizonte: Ed. da UFMG, 1999.

CHAVES, S.; CAMPELLO, M. A qualidade e a evolução das normas série ISO 9000. XIII Simpósio de Excelência na Gestão e Tecnologia, 2016.

FERNÁNDEZ, A. P.; MATEO, M. O. Impacto de la norma ISO 9001: 2015 en el ámbito de la ingeniería. Integración en las PYMEs. Revista Dyna, v. 91, n. 2, p. 118121, 2016. Disponivel em < https://www.researchgate.net/publication/291945228_Impacto_de_la_norma_ISO_90 012015_en_el_ambito_de_la_Ingenieria_Integracion_en_las_Pymes >

FONSECA, L. M. From Quality Gurus and TQM to ISO 9001: 2015: a review of several quality paths. International Journal for Quality Research (IJQR), v. 9, n. 1, p. 167-180, 2015.2 Disponivel em < https://www.researchgate.net/publication/273698022_FROM_quality_gurus_and_TQ M_to_ISO_90012015_A_review_of_several_quality_paths >

INTERNATIONAL ORGANIZATION FOR STANDARDIZATION (2015). ISO Survey 2017, 2017. Disponível em: <http://www.iso.org> Acesso em: 26 de Outubro de 2018.

LIKERT, R. A technique for the measurement of attitudes. Archives of psychology, 1932.

ROA, J. A. S.; DULCIC, F.J.L.; CARRIZO, L.D.A.; ALCAYAGA, C.I.P.; CARMONA, C.M.G.; Actitud y resistencia al cambio organizacional en trabajadores mineros. 
Revista de Psicologia, v. 36, n. 1, p. 105-134, 2018. Disponível em < http://revistas.pucp.edu.pe/index.php/psicologia/article/view/15205/pdf>

RIBEIRO, O.P. Cultura organizacional. Millenium, n. 32, p. 169-184, 2016. Disponível em: < https://revistas.rcaap.pt/millenium/article/view/8401>

SILVA, F. P.; CINTRA M. Curso cultura organizacional. Módulo II: líder na gestão pública. Porto Alegre: Escola de gestão Pública/EGP, p. 37, 2015.

TAJRA, S. F. Gestão estratégica na saúde: reflexões e práticas para uma administração voltada para a excelência. In: Gestão estratégica na saúde: reflexões e práticas para uma administração voltada para a excelência, 2008. 